\title{
Critical Performance Parameters of Distance Education through e-Learning: A Case Study in Kuwait
}

\author{
Rabab Dawoud Alsaffar
}

\begin{abstract}
Distance education through e-learning is gaining popularity in developing countries like Kuwait; however, its success depends upon the acceptance of this mode of learning by the students. Thus, there is a need to identify the performance parameters as perceived by the users. This research has identified the critical performance parameters of E-learning technologies used in distance education as perceived by the users. The research was theoretically based on Technology Acceptance Model. The research methodology involved the use of Structural Equation Modelling using Partial Least Square Method. The data was collected through a self-administered questionnaire by 216 students in Kuwait, who have used the E-learning technologies in the distance mode of education. The study indicated that perceived usefulness of E-learning technologies had an influence on attitude towards using as well as behavioural intention of use; perceived ease of use had influence on attitude towards using as well as perceived usefulness; attitude towards using had a significant influence on behavioural intension to use; and behavioural intension to use had a significant influence on actual system use. Surprisingly, attitude towards using had no influence on actual system use. Based on these revelations of the study suggestions have been made to the strategic planners in the Public Authority for Applied Education \& Training of Kuwait to popularize distance education to a higher level.
\end{abstract}

Index Terms-Distance education, e-learning, technology acceptance model.

\section{INTRODUCTION}

In today's fast paced world, technology has invaded almost all walks of life. In the context of learning, the Information and Communication Technologies (ICT) have made a tremendous impact even at the global scenario and e-learning technologies are a class apart from the rest. To support the fast paced growth, the new mode of education essentially the Distance Education, where students and teachers are physically separated is becoming popular day by day. The reasons are many which include: flexibility to decide on the pace of study, flexibility on the place and time of study, ability to get a degree from any part of the world, ability to pursue studies without taking a break from work, acquire degrees at lower costs, make use of the technology driven classrooms, structured approach to learning, better monitoring of progress, etc. The distance education is mainly supported by the E-learning technologies. In the past the

Manuscript was received September 23, 2017; revised May 13, 2018. The work has been carried out by self-financing basis with academic research in focus.

Rabab Dawoud Alsaffar is with the Public Authority for Applied Education and Training, College of Basic Education, Female Campus, Kuwait (e-mail: rd.alsaffar@paaet.edu.kw). e-learning technologies were mainly in the form of mainframe computers, floppy discs, multimedia CD-ROMS, video tapes etc., and currently they are mainly web based technologies in the form of internet, intranet or extranet, and in the future they are going to be in the form of M-Leaning (Mobile learning).

Kuwait is rich in its oil revenues, but having realized the importance of educated population, it has put education to the public in the forefront of its national agenda. Measures have been taken to educate the younger population through quality schooling and the adult population through sponsorship to the higher educational institutes in Kuwait or abroad, particularly in the Western Countries. The two major challenges faced in imparting education are: first, the cost of education; and second, the discontinuity of service in case of employed personnel during the period of education. One of the effective solutions to address both these challenges is Distance Education, which is the primary reason for its popularity in Kuwait. However, the concept is yet to gain full momentum due to the lack of awareness and lack of system use and absorption of e-learning technologies in the Kuwaiti educational market. Thus, there is a need to identify the critical performance factors which would facilitate the system use in the context of e-learning.

The distance education mode of e-learning could be either synchronous or asynchronous, while the former refers to real time learning i.e., teacher teaching in real time, and the latter refers to teaching and learning at different times through the web-content [1]. Both these forms of e-learning through distance education have their own set of merits and demerits. Thus, the distance education supported well by e-learning technologies has a long way to go and its success mainly depends upon the perceptions of the learners and this research is focussing specifically on the application of Technology Acceptance Model (TAM) to identify the critical performance parameters.

Objectives of the Study:

1) Identify the performance parameters which would lead to system use in the context of E-Learning technologies in Distance Education.

2) Develop the structural model to seek inter-relationships between the dimensions of Technology Acceptance Model.

3) Investigate the empirical relationships between the dimensions of study and identify the critical performance parameters of system use in E-learning technologies.

4) Develop suggestions to the strategic managers of Public Authority for Applied Education \& Training in Kuwait to enhance the system use and popularize distance education. 


\section{ReSEARCH Methodology}

\section{A. The Conceptual Model}

Technology Acceptance Model (TAM) [2] is of relevance even today for its versatility and relevance in terms of adoption of technology for a given application. E-learning technologies have a great role to play in distance education mode of learning as teacher is physically separated from the students and the approach is mainly learner-centric.

The degree to which the user perceives that the technology is easy to use was linked to the perception of the user about the usefulness of the technology in use [2]-[5]. Both Perceived Ease of Use (PEU) and Perceived Usefulness (PRU) are multi-dimensional constructs. The PEU by a person is found to be dependent on two aspects: anchor and adjustment [6]. Anchor comprises computer self-efficacy, perception of external control, computer anxiety, and computer playfulness. Adjustment comprises perceived enjoyment derived in the usage of technology and objective usability of technology. PRU of technology has a host of attributes attached to it which includes: subjective norms, image, job relevance, output quality, and result demonstrability [7]. In addition, it was also found that individual differences, system characteristics, social influence, and facilitating conditions also had their role to play in PRU [7]. Hence, it is imperative that PEU and PRU may have an association with each other.

Attitude towards doing something is explained very well by The Theory of Reasoned Action (TRA) [8]. According to the TRA belief of a person about something forms an attitude towards it, which can lead to an intention. Further, the intention in turn can develop a particular type of behaviour. Attitude of a person may be developed also through 'subjective norms' of the person, which is basically through the influence of an individual or a group whom the person considers to be important. This implies that the PEU of a person as well as the PRU can lead to an Attitude towards Using (ATU) the E-learning tools [9]. Further, the TRA also implies that PRU can make the person develop a Behavioural Intention to Use (BIU). The modified TRA has led to Theory of Planned Behaviour (TPB) which claims that while interaction of attitude and subjective norms can form intention, the interaction between subjective norms and perceived behavioural control can also lead to the formation of intention. Further, the interaction between attitude and perceived behaviour control can form attitude as well as behaviour. While the TPB is generic in nature and is applicable to many different contexts mainly in studying the consumer behaviour in marketing, the concept has been also borrowed by the TAM. In the context of this research, ultimately the Actual System Use (ASU) with respect to E-learning technologies is under focus, and hence, the hypothetical model needs to be tested empirically "Fig. 1".

Following are the hypotheses formulated in terms of the perceptions of the students with respect to E-learning technology usage in distance education mode of learning.

H1: There is a significant influence of perceived ease of use on perceived usefulness.

$\mathrm{H} 2$ : There is a significant influence of perceived ease of use on attitude towards using.
H3: There is a significant influence of perceived usefulness on attitude towards using.

H4: There is a significant influence of perceived usefulness on behavioural intention to use.

H5: There is a significant influence of attitude towards using on actual system use.

H6: There is a significant influence of attitude towards using on behavioural intention to use.

H7: There is a significant influence of behavioural intention to use on actual system use.

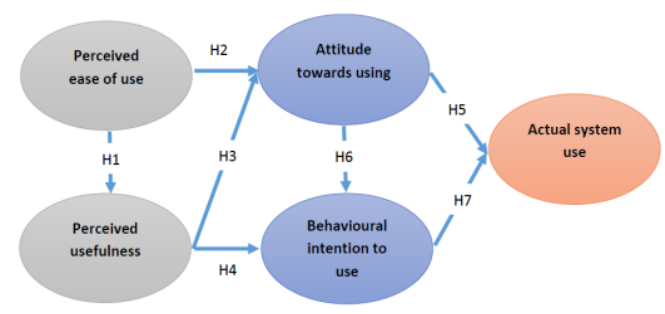

Fig. 1. The hypothetical research model.

\section{B. Data Selection}

The data collected in this research is from 216 students through simple random sampling from a sample of 600 students who had enrolled for distance education at bachelor degree programme in The Public Authority for Applied Education \& Training, Kuwait. The sample size estimate was through a standard formula. While 224 filled questionnaires were collected, eight were erroneous or incomplete and hence were discarded.

\section{The Metric}

The metric was in the form of a self-administered questionnaire which had two parts. The first part included general Likert 5-point scale statements (5-strongly agree and 1 -strongly disagree) and the second part had three qualitative questions to understand general perceptions about E-learning. While the former was used for quantitative analysis, the latter was used for obtaining some general perceptions about the E-learning through distance mode of education.

\section{Data Analysis}

The data analysis was mainly through Structural Equation Modelling (SEM) using Partial Least Square Method (PLSM). This second generation statistical analysis was specifically chosen as there was a need to conduct Confirmatory Factor Analysis (CFA) and regression analysis simultaneously because of the multicollinearity which was to be tested. The tool used was SmartPLS $®$ for SEM. CFA was adequate as the questionnaire used was a derivative of standard questionnaire used in evaluating the Technology Acceptance Model, which had already a proved reliability and validity. However, a few minor changes were required in the questionnaire as the context was distance education and the instrument was not developed for this context.

\section{RESULTS AND ANALYSIS}

\section{A. Comparative Analysis}

The comparative analysis of the chosen dimensions of 
Technology Acceptance Model has indicated that the perceived ease of use of E-learning technologies in distance mode of education is the top ranked dimension followed by actual system use. The least ranked dimension is perceived usefulness followed by attitude towards using. Behavioural intention to use is in the mid-rank "Table 1" and "Fig. 2".

\begin{tabular}{|l|r|l|l|}
\multicolumn{5}{|c|}{ TABLE I: RANKING OF DIMENSIONS } \\
\begin{tabular}{|lrl|l|}
\hline Dimension & Std. Dev. & Mean & Rank \\
\hline PEU & 1.35 & 3.08 & 1 \\
\hline PRU & 1.17 & 2.78 & 5 \\
\hline ATU & 1.24 & 2.80 & 4 \\
\hline BIU & 1.22 & 2.91 & 3 \\
\hline ASU & 1.07 & 2.98 & 2 \\
\hline
\end{tabular}
\end{tabular}

Legend:

$\mathrm{ASU}=$ Actual System Use; ATU = Attitude towards Using; BIU = Behavioural Intension to USE; PEU = Perceived Ease of USE; PRU = Perceived Usefulness

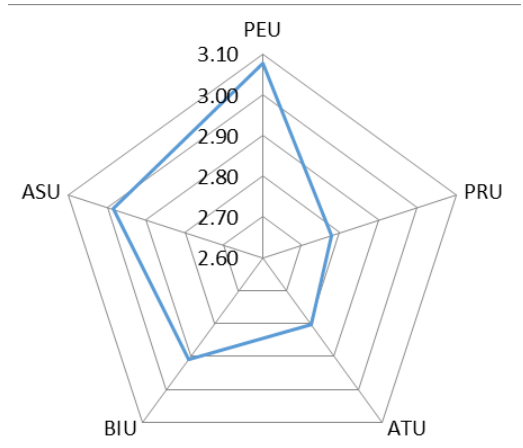

Fig. 2. Radar diagram of dimensions.

\section{B. Structural Equation Modelling}

Measurement Model: The latent variable reliability, internal consistency, item reliability and composite reliability prove the reliability of the measurement of data. Cronbach's alpha coefficients range from 0.6 to 0.9 , indicate a moderate to high level of internal consistency. The composite reliability estimate also ranges from 0.83 to 0.96 indicating high reliability values "Table I". The results of the convergent validity assessed based on factor loading (>0.8) indicate a strong effect of the factor on the variable of study "Table II". Discriminant validity measured through the comparison of the square root of average variance extracted (AVE) for each construct compared with the correlation between the construct and the other constructs indicates acceptable discriminant validity between each pair of construct, with all AVE square roots greater than the correlation between the constructs "Table III". The R2 values are all above the cut of value of 0.1 and range from 0.1 to 0.8 which indicates a very good model fit in terms of the percentage variance of the independent variables expressing their influence on the dependent variable (as high as $80 \%$ ).

TABLE II: THE RELIABILITY MEASURES OF THE DATA

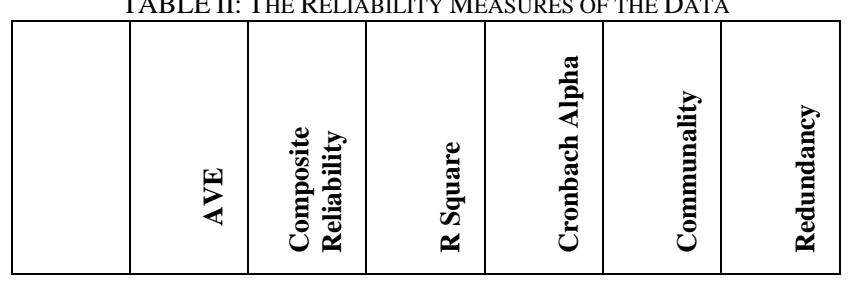

\begin{tabular}{|l|l|l|l|l|l|l|}
\hline ASU & 0.76 & 0.90 & 0.53 & 0.84 & 0.76 & 0.15 \\
\hline ATU & 0.76 & 0.91 & 0.45 & 0.84 & 0.76 & 0.27 \\
\hline BIU & 0.90 & 0.96 & 0.79 & 0.94 & 0.90 & 0.49 \\
\hline PEU & 0.93 & 0.97 & 0.00 & 0.96 & 0.93 & 0.00 \\
\hline RU & 0.75 & 0.90 & 0.09 & 0.83 & 0.75 & 0.06 \\
\hline
\end{tabular}

TABLE III: FACTOR LOADINGS

\begin{tabular}{|c|c|c|c|c|c|}
\hline & ASU & ATU & BIU & PEU & PRU \\
\hline ASU1 & 0.85 & & & & \\
\hline ASU2 & 0.84 & & & & \\
\hline ASU3 & 0.91 & & & & \\
\hline ATU1 & & 0.86 & & & \\
\hline ATU2 & & 0.93 & & & \\
\hline ATU3 & & 0.83 & & & \\
\hline BIU1 & & & 0.90 & & \\
\hline BIU2 & & & 0.98 & & \\
\hline BIU3 & & & 0.96 & & \\
\hline PEU1 & & & & 0.96 & \\
\hline PEU2 & & & & 0.96 & \\
\hline PEU3 & & & & 0.97 & \\
\hline PRU1 & & & & & 0.77 \\
\hline PRU2 & & & & & 0.88 \\
\hline PRU3 & 0.00 & 0.00 & 0.00 & & 0.94 \\
\hline
\end{tabular}

\begin{tabular}{|l|r|r|r|r|r|}
\multicolumn{7}{|c|}{ TABLE IV: INTER-ITEM CORRELATIONS } \\
\hline & \multicolumn{1}{|c|}{ ASU } & \multicolumn{1}{c|}{ ATU } & \multicolumn{1}{c|}{ BIU } & PEU & \multicolumn{1}{|c|}{ PRU } \\
\hline ASU & $\mathbf{0 . 8 7}$ & 0 & 0 & 0 & 0 \\
\hline ATU & 0.6298 & $\mathbf{0 . 8 7}$ & 0 & 0 & 0 \\
\hline BIU & 0.7205 & 0.7703 & $\mathbf{0 . 9 5}$ & 0 & 0 \\
\hline PEU & 0.3928 & 0.6037 & 0.4828 & $\mathbf{0 . 9 6}$ & 0 \\
\hline PRU & 0.5754 & 0.4638 & 0.7511 & 0.3069 & $\mathbf{0 . 8 6}$ \\
\hline
\end{tabular}

\begin{tabular}{|c|c|c|c|c|c|}
\hline & 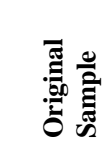 & 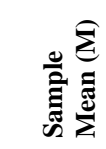 & 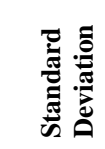 & 宽 & 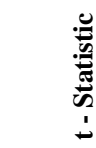 \\
\hline $\begin{array}{l}\text { PEU -> PRU } \\
(\text { H1) }\end{array}$ & 0.31 & 0.32 & 0.09 & 0.09 & 3.44 \\
\hline $\begin{array}{l}\text { PEU -> } \\
\text { ATU (H2) }\end{array}$ & 0.51 & 0.51 & 0.06 & 0.06 & 8.16 \\
\hline $\begin{array}{l}\text { PRU -> } \\
\text { ATU (H3) }\end{array}$ & 0.31 & 0.31 & 0.10 & 0.10 & 3.04 \\
\hline $\begin{array}{l}\text { PRU -> BIU } \\
\text { (H4) }\end{array}$ & 0.50 & 0.49 & 0.06 & 0.06 & 8.17 \\
\hline $\begin{array}{l}\text { ATU -> } \\
\text { ASU (H5) }\end{array}$ & 0.18 & 0.19 & 0.13 & 0.13 & 1.41 \\
\hline $\begin{array}{l}\text { ATU -> BIU } \\
\text { (H6) }\end{array}$ & 0.54 & 0.55 & 0.05 & 0.05 & 10.80 \\
\hline $\begin{array}{l}\text { BIU -> ASU } \\
\text { (H7) }\end{array}$ & 0.58 & 0.58 & 0.12 & 0.12 & 4.74 \\
\hline
\end{tabular}

Structural Model: The results indicate that out of the seven hypotheses being tested six are supported "Table V" and "Fig. 3".

Following hypotheses were supported: 
$\mathrm{H1}$ : There is a significant influence of perceived ease of use on perceived usefulness.

$\mathrm{H} 2$ : There is a significant influence of perceived ease of use on attitude towards using.

$\mathrm{H} 3$ : There is a significant influence of perceived usefulness on attitude towards using.

$\mathrm{H} 4$ : There is a significant influence of perceived usefulness on behavioural intention to use.

H6: There is a significant influence of attitude towards using on behavioural intention to use.

H7: There is a significant influence of behavioural intention to use on actual system use.

Following hypothesis is not supported:

H5: There is a significant influence of attitude towards using on actual system use.

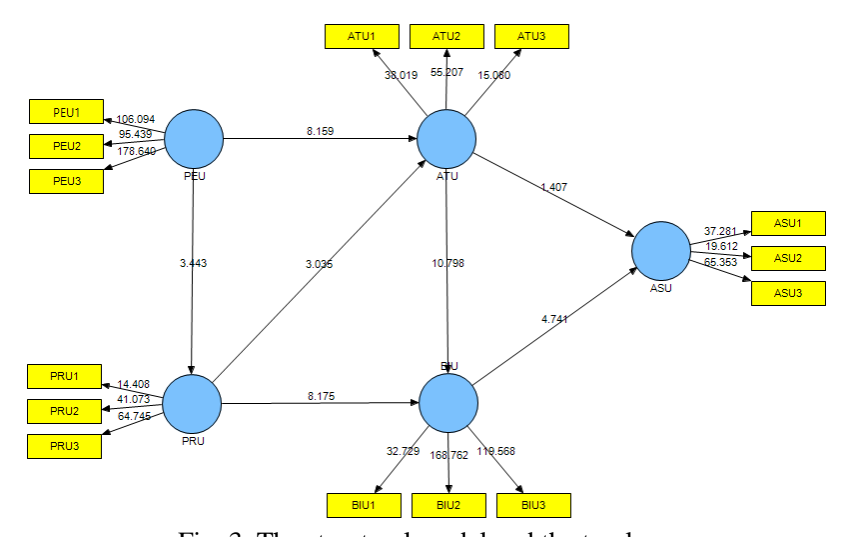

Fig. 3. The structural model and the t-values.

\section{RESUlts AND ANALYSIS}

The empirical testing of the hypothetical model has revealed the significance of relationships between the dimensions of this study. These revelations have led to the following suggestions to the strategic managers so as to make E-learning more popular in the context of distance education in Kuwait.

The perceived ease of use of E-learning technologies in distance mode of education was the dimension which was highly ranked by the students in comparison to the other dimensions of study, which implies that the students are convinced to a great extent about the user friendliness of the tools and technologies that they have been using in their learning processes. However, there is always a scope for further improvement. The advancement in the disciplines offered through distance education may offer higher level of challenges in making the students comprehend the concepts and theories and also their practical implications. So, there is a need to innovate on the technologies on a continual basis in making learning an enjoyable process for the learners.

The actual system use being the second highly ranked dimension by the students of distance education, the implication is that the students have made good use of the systems and the processes available to them in the distance education mode of learning. It is a known fact that the higher the system use by students, the better will be their performance in terms of outcome achievement in those areas of study. As there are tools available to keep track of the system use by each student, it helps to identify the amount of interest the student has shown in learning the course. It would be beneficial if a mobile application is developed which not only keeps track of the student system usage, but also prompts him/her to spend the required number of hours on the system in learning as per the time table.

The concern is about the least ranked dimension perceived usefulness followed by attitude towards using. The indication is that the students are not fully aware about the usefulness of the E-learning technologies available to them while pursuing their studies in the distance mode. Perceived usefulness can be improved through contact programmes, mobile messages, word of mouth, and counselling sessions. E-learning technologies may be of very high standards in terms of their usability but unless the students have perceived their usefulness in learning the courses they may not make use of those technologies. It is always the perceptions of people about a tool or technology that makes them spend time on it for their benefit and if the perceptions are not positive they may not make an attempt to use them. Demonstration sessions in which the usefulness of the E-learning technologies is made known to the students may help in building a positive perception about the technology and its usage. So, when students enrol for a programme, a few demonstration sessions may be arranged at students' convenience to acclimatise the students with the E-learning technologies.

The other weaker dimension is attitude towards using E-learning technologies. Both the perceived usefulness and attitude towards using have almost same mean (about 2.8; Std. Dev. about 1.2) which implies that these two dimensions of TAM are closely related. In other words, if the perceptions are positive the attitude towards using will be positive and vice versa. This once again calls for a perception building exercise to be conducted for the benefit of the students on distance mode of learning. The regular full time students attending the classes in the conventional mode of learning are always in touch on daily basis with their classmates and peer group so through the 'word of mouth' their perceptions may be influenced, but in case of distance education students such contacts are very minimal so perception building may have to be through other mediums. Social network in the form of Facebook, Twitter, LinedIn, WhatsApp, Instagram etc., could be used effectively for developing positive perceptions about the E-learning technologies.

The path between perceived ease of use, perceived usefulness, attitude towards using, behavioural intension to use, and actual system use is supported through hypothesis testing. This outcome is in alignment with several earlier studies (e.g., [3], [7], and [10]). The implication is that ease of use of the E-learning technologies as perceived by the students of distance education should be enhanced, which can ultimately lead to system use. The most common E-learning involves web-based learning, computer-based learning, virtual classroom, and digital collaboration. The content will be delivered through internet, intranet, extranet, videotape, television, etc. While using these many different forms of learning, which support the distance education, the managers must place the ease of use of these technologies to be the top of priority. The present context of study was at the graduate level of education mainly on management education. So, these E-learning technologies must bring many different 
approaches to learning using scenario-based learning, case-based learning, problem-based learning, project-based learning, design-based learning, role-play-based learning and many more.

The E-learning environment could be a web site, smart phone, iPod, webcam etc., and social media such as Facebook, MySpace, Wiki, blogs, twitter, YouTube, etc., can be very handy to disseminate messages and information effectively. The revelation through hypothesis testing is that general instructions in the use of technology or accomplishing an academic task must be made as simple as possible and in a country like Kuwait translation in Arabic would facilitate ease of use to a great deal. Again, it is the perceived ease of use that matters to the students and the gap between the perceptions and reality should be minimal if not zero.

Perceived usefulness is a relative term and there are chances that even though the E-learning technology is quite useful in disseminating knowledge in the mode of distance education based learning, the students may still perceive it to be less useful. The reasons could be many, for instance the word of mouth may influence the perception of a student about the usefulness of E-learning technologies in distance education. So, the implications to the managers of distance education are that the students have to be given orientation to the distance mode of education and the usefulness of this mode has to be made explicit. Experiences of senior students have to be shared with the new students so that they may perceive the usefulness before they make use of the E-learning technologies.

Attitude towards using E-learning had no significant influence on actual system use and this outcome corroborates with the finding of a group of researchers (e.g., [11]), however, it does have a significant influence on behavioural intention to use. According to the Theory of Reasoned Action it is the beliefs which forms attitude and while beliefs can be influenced, once the beliefs have formed certain attitudes it is not easy or rather impossible to change those attitudes [8]. So, the ideal approach would be to make the students believe in the usage of E-learning technologies in making the educational experience a lasting one. Explaining to the students the richness of technological support to learning that can be provided by the E-learning technologies, the superior system quality and information quality, the timeliness and speed of service delivery [12] through media and other means would strengthen their belief in the efficiency of the education system in the distance mode and develop a positive attitude towards it.

\section{CONCLUSIONS}

As Kuwait is planning to improve e-Learning qualitatively and quantitatively, the distance mode of education is becoming the major beneficiary, however; it is wise to inspect the progress periodically. This research applied the theory behind the Technology Acceptance Model to a practical situation to test if the users had accepted the newer mode of learning through E-Learning technologies in the context of distance education. It was evident through the empirical results that the perceived ease of use and actual system use were ranked relatively higher by the users thus proving the success of E-Learning tools to a considerable extent. However, there were areas of improvement required in attitude towards using and perceived usefulness which has to be considered by the policy makers on distance mode of education and measures must be taken to improve upon these two dimensions to further popularize the distance mode of learning using E-Learning technologies. This research is quite timely as the country is geared towards modernization of education system and the suggestions may be considered by the Public Authority for Applied Education \& Training of Kuwait for the benefit of the students and the growth of distance education.

\section{REFERENCES}

[1] L. A. Diaz and F. B. Entonado, "Are the functions of teachers in e-learning and face-to-face learning environments really different?" Educational Technology \& Society, vol. 12, no. 4, pp. 331-343, April 2009

[2] F. D. Davis, "A technology acceptance model for empirically testing new end-user information systems: Theory and results," $\mathrm{PhD}$ dissertation, Cambridge, MA: MIT Sloan School of Management, 1989.

[3] S. Y. Park, An Analysis of the Technology Acceptance Model in Understanding University Students' Behavioral Intention to Use E-Learning, Educational Technology \& Society, vol. 12, no, 3, pp. 150-162, March 2009.

[4] B. A. Al-alak and L. A. M. Alnawas, "Measuring the acceptance and adoption of e-learning by academic staff," Knowledge Management \& E-Learning: An International Journal, vol. 3, no. 2, pp 201-221, February 2011.

[5] S. Okazaki and L. M. Santos, "Understanding e-learning adoption in Brazil: Major determinants and gender effects," The International Review of Research in Open and Distance Learning, vol. 13, no. 4, pp. 91-106, April 2012.

[6] P. C. Lai, "The literature review of technology adoption models and theories for the novelty technology," Journal of Information Systems and Technology Management, vol. 14, no. 1, pp. 21-38, Jan. 2017.

[7] V. Venkatesh and F. D. Davis, "A theoretical extension of the technology acceptance model: Four longitudinal filed studies," Management Science, vol. 46, pp. 186-204, May 2000,

[8] M. Fishbein and I. Ajzen, Belief, Attitude, Intention, and Behavior: An Introduction to Theory and Research, Ontario: Addison-Wesley Pub. Co., ch. 3, 1975.

[9] R. M. Baron and D. A. Kenny, "The moderator-mediator variable distinction in social psychological research: Conceptual, strategic, and statistical considerations," Journal of Personality and Social Psychology, vol. 51, no. 6, pp. 1173-1182, June 1986.

[10] Q. L. Huynh and T. L. E. Thi, "The mediating role of the perceived usefulness in the acceptance of e-learning," International Journal of Humanities and Social Science Invention, vol. 3, no. 2, pp. 2319-7714, February 2014.

[11] Y. Y. Mun, D. J. Joyce, S. P. Jae, and C. P. Janice, "Understanding information technology acceptance by individual professionals: Toward an integrative view," Information \& Management, vol. 43, pp. 350-363, Jan 2006.

[12] A. Y. Alsabawy, A. Cater-steel, and J. Soar, "Determinants of perceived usefulness of e-learning systems," Computers in Human Behaviour, vol. 64, pp.843-858, Feb 2016.

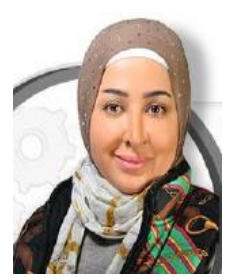

Rabab Dawoud Alsaffar was born and brought up in Kuwait. She has done her M.Sc. from the University of Glamorgan in UK, and PhD from York University, UK. The major field of study of study has been in Electronic Educational Games. She is currently employed at the Public Authority for Applied Education \& Training of Kuwait, College of Basic Education, Female Campus as assistance professor teaching courses in educational 